\title{
Hormonal Regulation of the Shape of Identified Motoneurons in the Moth Manduca sexta
}

\author{
James W. Truman and Shirley E. Reiss \\ Department of Zoology, University of Washington, Seattle, Washington 98195
}

\begin{abstract}
Motoneurons $\mathrm{MN}-1$ and $\mathrm{MN}-3$ in the moth Manduca sexta go through 3 distinct phases during postembryonic life. During larval life their neuritic fields show allometric growth in concert with larval growth. Larval neurites are then lost during the larval-pupal transition, which is followed by the outgrowth of adult-specific neurites during adult development. In MN-1, the adult-specific arbor typically results from the outgrowth of neurites ipsilateral to the cell body. However, in a small percentage of cells, ipsilateral branches are not present and contralateral branches extend across the midline to fill the vacant space. This altered form of $\mathrm{MN}-1$ is thought to result from the early failure of ipsilateral neurite extension.
\end{abstract}

The steroid hormones, the ecdysteroids, are responsible for the outgrowth of adult neurites. The onset of the latter is correlated with the ecdysteroid increase that promotes adult differentiation and does not occur under conditions such as diapause, in which the normal steroid rise is absent. Artificial replacement of ecdysteroids, however, induces the adult-specific growth. This action of ecdysteroids to cause a change in neuronal form requires the absence of juvenile hormone ( $\mathrm{JH}$ ). Application of $\mathrm{JH}$ mimics prior to the onset of the program of adult outgrowth blocks this outgrowth. MN-1 and $\mathrm{MN}-3$ show different times of JH sensitivity, which appear to be correlated with different times of neurite outgrowth. It is concluded that the role of $\mathrm{JH}$ is to maintain the status quo of central neurons and prevent changes in form in response to ecdysteroids. In the absence of $\mathrm{JH}$, the ecdysteroids can then exert morphogenetic changes, but the nature of these actions, neurite outgrowth or regression, is likely a function of the developmental history of the cell.

Even after initial differentiation is completed and synaptic contacts are established, functional neurons sometimes show dramatic changes in their structure and function. For example, in the nematode Caenorhabdites elegans, the DD motoneurons in the ventral cord completely change their patterns of connectivity during the period preceding the first larval molt (White et al., 1978). In insects that undergo complete metamorphosis, many larval neurons show substantial changes in their central and

\footnotetext{
Received Aug. 29, 1986; revised June 29, 1987; accepted Aug. 26, 1987.

This work was supported by grants from the NSF (DBC-8316055), NIH (NS 13079), and the McKnight Foundation. We thank Professor L. M. Riddiford and Dr. S. Fahrbach for a critical reading of the manuscript. The comments of an anonymous reviewer are also gratefully acknowledged.

Correspondence should be addressed to Dr. J. W. Truman, Department of Zoology NJ-15, University of Washington, Seattle, WA 98195.

Copyright (C) 1988 Suciety for Neuroscience 0270-6474/88/030765-11\$02.00/0
}

peripheral connections as they are reorganized for their new role in the adult (Casaday and Camhi, 1976; Truman and Reiss, 1976; Levine and Truman, 1982, 1985). This ability of neurons to adopt alternate functional and anatomical states during postembryonic life is not limited to the invertebrates. In frogs, the trigeminal motoneurons of the tadpole are respecified to innervate the new jaw musculature of the adult (Alley and Barnes, 1983; Barnes and Alley, 1983). In birds, mammals and anurans, neurons in certain brain areas show disproportionate changes in size and dendritic branches during the adult maturation of one sex or the other (Greenough et al., 1977; DeVoogd and Nottebohm, 1981; Gurney, 1981; Kelley and Fenstemaker, 1983; Kurz et al., 1985).

In many of the above cases, the changes in neuronal form and function result from hormones acting on the CNS. In vertebrates, exposure to gonadal steroids is necessary for neurons to attain their sex-specific morphologies (Gurney, 1981; Arnold and Gorski, 1984). Thyroxin regulates metamorphosis in amphibians (Kollros, 1981), and some aspects of postmetamorphic neuronal growth have been shown to be in direct responsc to this hormone (Hoskins and Grobstein, 1985). In insects, the hormones involved in molting and metamorphosis, the ecdysteroids and juvenile hormones $(\mathrm{JH})$, regulate the expansion of the terminal axon arbors of sensory neurons (Levine et al., 1986) and the regression of dendritic fields of identified motoneurons (Weeks and Truman, 1985, 1986). The present paper describes the pattern of dendritic outgrowth in specific motoneurons during metamorphosis of the moth Manduca sexta and examines the relationship of this growth to the endocrine changes that cause metamorphosis.

\section{Materials and Methods}

Experimental animals. Larvae of Manduca sexta were reared on an artificial diet after the method of Bell and Joachim (1976) at $26 \pm 1^{\circ} \mathrm{C}$. Under these conditions, the interval from hatching to the cessation of feeding and the initiation of wandering by the fifth (last) instar larva is about $14 \mathrm{~d}$. Four days then elapse between wandering and pupal ecdysis and another $20 \mathrm{~d}$ until the emergence of the adult moth. During the early phases of adult development, we staged insects according to the number of days since pupal ecdysis. Older animals were staged using the timetable in Schwartz and Truman (1983) by reference to external features of the developing moth that were visible through the overlying pupal cuticle. Larvae were usually reared under "long-day" photoperiods (17L:7D), which allowed continuous development from the larval to the adult stage. Some were reared under a short-day photoperiod (12L:12D), which caused an arrestment of development, termed "diapause," in the pupal stage. The gross appearance of the CNS and musculature of diapausing pupae is similar to that of long-day-reared animals $2 \mathrm{~d}$ after pupal cedysis. The diapausing condition is maintained for a number of months and is terminated by the secretion of ecdysteroids to bring about adult differentiation. Emergence of the adult occurs about $18 \mathrm{~d}$ after the termination of diapause. 

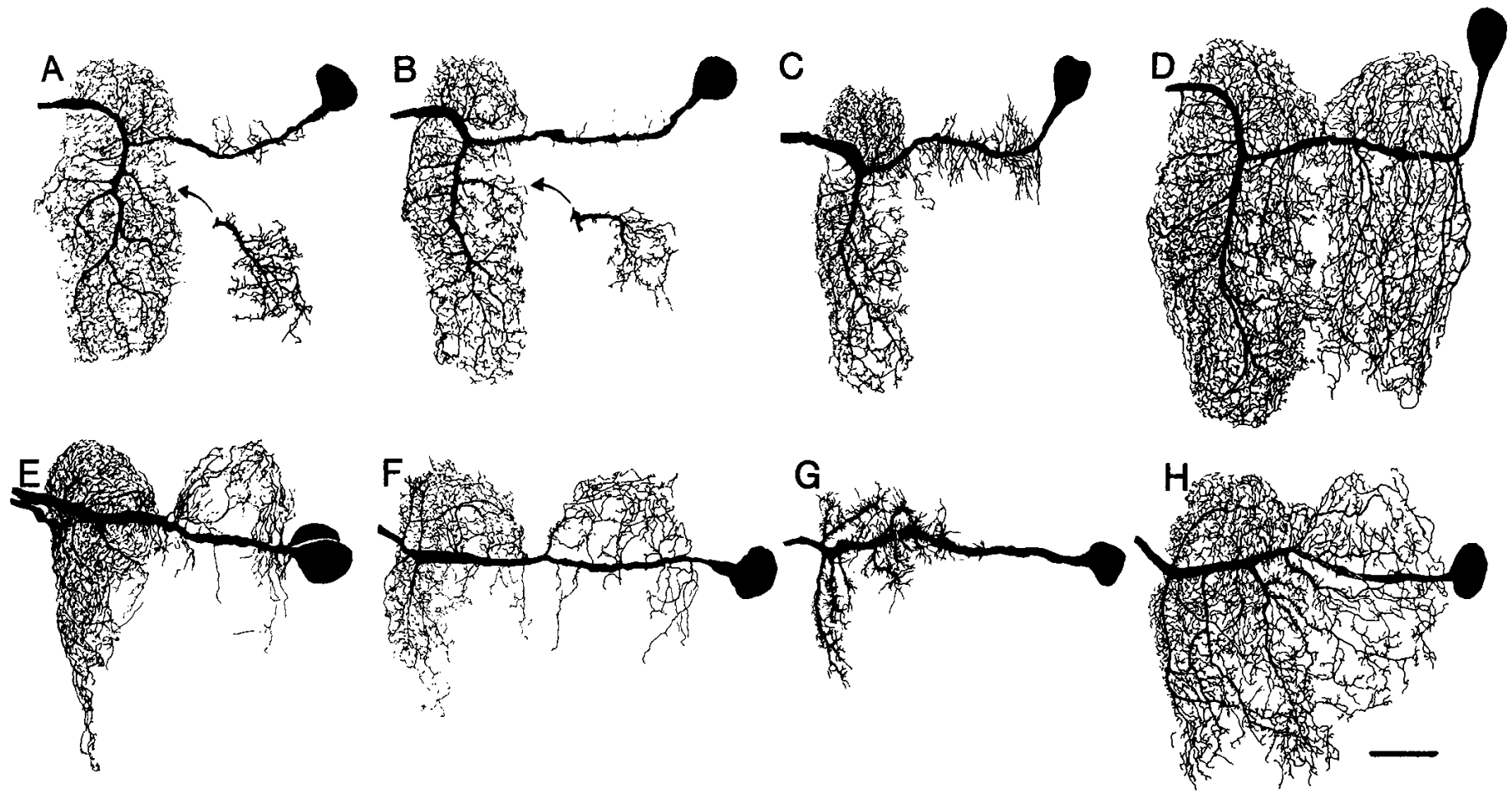

Figure 1. Drawings of cobalt fills of abdominal motoneurons MN-1 $(A-D)$ and $\mathrm{MN}-3(E-H)$ at various times during the life history of $M a n d u c a$ sexta. Cells were filled on day 3 of the fifth larval instar $(A, E)$, the day of pupal ecdysis $(B, F), 3 \mathrm{~d}$ after pupal ecdysis $(C, G)$, and in the adult $(D$, $H$ ). The second cell body seen in $E$ is due to the simultaneous filling of $\mathrm{MN}-2$ in that example. The insets in $A$ and $B$ are enlargements of a secondary contralateral branch showing the reduction in fine branches that occurs during the larval-pupal transition. Scale bar, $50 \mu \mathrm{m}$; for the insets, $30 \mu \mathrm{m}$.

Anatomical techniques. The morphology of specific motoneurons was revealed by backfilling the branches of peripheral nerves with $\mathrm{CoCl}_{2}$. Ganglia were excised, placed in saline (Levine and Truman, 1982), and the appropriate nerve branch extended across a paraffin oil barrier into a drop of distilled water. The branch was recut and, after 10-20 sec, the water replaced with $2 \% \mathrm{CoCl}_{2}$. Neurons were filled overnight at $4^{\circ} \mathrm{C}$. Early in metamorphosis the CNS becomes very fragile as the perineurium is undergoing reorganization (McLaughlin, 1974). Such nervous systems were lightly fixed for $30 \mathrm{~min}$ in $2 \%$ paraformaldehyde before filling (Thomas et al., 1984). The fixed ganglia were then rinsed in saline and backfilled as described above. The prefixing allowed filling of the fine processes of growth cones that were typically blebby and distorted in unfixed material. Ganglia were immersed in either a dilute solution of ammonium sulfide or saline saturated with hydrogen sulfide gas to precipitate the saline. The cobalt was then intensified using the wholemount technique of Bacon and Altman (1977).

For the neurons examined in the present study, major portions of their dendritic arbors could be viewed in whole-mount preparations unobstructed by the processes of other cells that filled through the same peripheral branch. The dendritic arbors were viewed at $250 \times$ and drawn using a camera lucida attachment on a Leitz Ortolux microscope at a final magnification of $520 \times$.

As with most arthropod motoneurons, those in Manduca had a dense, complex dendritic tree. A rough quantitation of the arbors was obtained with the method used by Weeks and Truman (1985) to study the dendritic regression of larval motoneurons. In brief, each drawing was overlaid with an acetate transparency marked with a grid of $2.5 \mathrm{~mm}$ squares. The outline of the hemineuropil was drawn, and the number of squares within the outline determined. We then counted the number of squares that contained processes of the neuron. A square was counted only once, irrespective of the number of processes it contained. The number of squares covered by the neuron divided by those included in the hemineuropil was termed the "dendritic extent."

The motoneurons analyzed in the present study had arbors in both hemineuropils. The designation of each arbor is given with reference to the cell body, i.e., ipsilateral or contralateral.

Hormonal preparations. Solutions of the ecdysteroid 20-hydroxyec- dysone (20-HE; Sigma Chemical, St. Louis, MO) were prepared in insect saline (Ephrussi and Beadle, 1936). The concentration was checked spectrophotometrically at $240 \mathrm{~nm}$, with a molar extinction coefficient of 12,670 (Meltzer, 1971). The material was injected into the insects through the dorsal thorax using a $50 \mu \mathrm{l}$ Hamilton syringe. For ccdysteroid infusions, a polyethylene catheter was implanted into the dorsal thorax and the ecdysteroid solution delivered at a rate of $2.5 \mu \mathrm{l} / \mathrm{hr}$ by means of a syringe fitted to a syringe pump.

For our studies on the effects of juvenile hormone, we used the juvenile hormone mimic (JHM) methoprene (Zoecon, Palo Alto, CA). This compound is an oil and $1 \mu \mathrm{l}$ was added to $1 \mathrm{ml}$ of light paraffin oil to make an approximately $1 \mu \mathrm{g} / \mu \mathrm{l}$ solution. The oil vehicle was used to insure the slow release of the mimic from the injected droplet (Riddiford and Ajami, 1973). Ten micrograms of the JHM was injected into the dorsal thorax of pupae and developing adults.

\section{Results}

Changes in motoneuron morphology through larval growth and metamorphosis

The most extensively studied neuron in Manduca is MN-1 (Truman and Reiss, 1976; Levine and Truman, 1982, 1985), a paired motoneuron found in each abdominal ganglion. Figure $1 A$ shows an example of the morphology of this cell on day 3 of the last larval stage. Its cell body is situated in the extreme anterolateral region of the ganglion. Its primary neurite extends across the dorsal region of the neuropil and exits through the contralateral dorsal nerve to innervate the DEO2 muscle in the larva (Levine and Truman, 1985). The cell has a dense arbor in the hemineuropil contralateral to the somata, with most of its branches arising from a single, caudally directed neurite. Only a few sparse branches are found ipsilateral to the cell body.

At the start of the pupal stage, $5 \mathrm{~d}$ later, the larval target muscle of MN-1 is still present. The central arbor of the mo- 


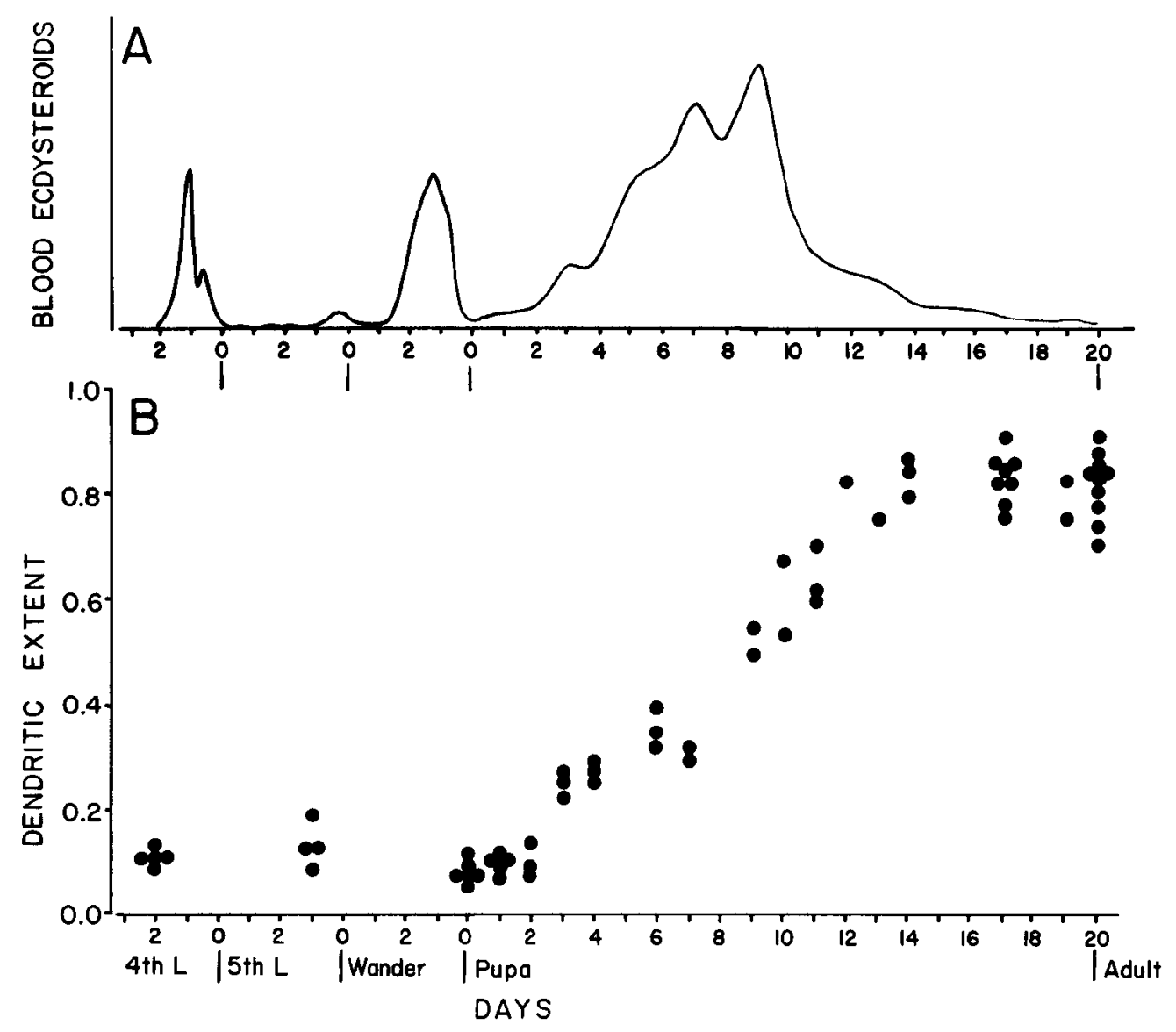

Figure 2, Relationship of the change in the ipsilateral dendritic arbor of $\mathrm{MN}-1$ with fluctuations in the blood edysteroid titer. $A$, The relative titer of ecdysteroids from the late fourth larval instar to the time of emergence of the adult moth (modified from Bollenbacher et al., 1981; Curtis et al., 1984). $B$, Changes in the ipsilateral neuritic field through the same period of time. Each dot represents the dendritic extent for individual $\mathrm{MN}-1$ neurons. 4th $L$, Fourth larval stage; 5 th $L$, fifth stage; Wander, wandering larva. toneuron (Fig. $1 B$ ) is slightly reduced with the loss of some higher-order branches. By $3 \mathrm{~d}$ later, the larval target muscle has degenerated and the motoneuron is initiating neurite outgrowth (Fig. 1C), the most obvious being ipsilateral to the cell body. Seventeen days later, at the emergence of the adult, MN-1 innervates a new muscle, DE4 (Levine and Truman, 1985). The contralateral arbor has re-elaborated its fine processes, and the neuron has grown a new, ipsilateral neuritic arbor that is unique to the adult form of the cell (Fig. $1 D$ ). This new arbor covers almost as much neuropil area as does the contralateral arbor, but it accomplishes this by the extension of numerous parallel branches from the primary neurite.

MN-3 is the other motoneuron examined in this study. In larvae, backfills of the anterior branch of the dorsal nerve typically filled both MN-2 and MN-3 (Fig. $1 E$ ) and revealed both ipsilateral and contralateral arbors. Intracellular fills of both cells at this stage, however, show that the ipsilateral arbor belongs cxclusively to MN-3 (Levine and Truman, 1985). MN-3 innervates a tergopleural muscle in the larva and the diffuse mat of tergosternal muscles in the adult (Levine and Truman, 1985). At pupal ecdysis (Fig. $1 F$ ), the ipsilateral portion of $\mathrm{MN}-3$ is similar to that seen in the day 3 fifth-stage larva (a dendritic extent of $0.25 \pm 0.08( \pm \mathrm{SD} ; n=4)$ and $0.32 \pm 0.04(n=5)$, respectively). During the next few days, however, MN-3 undergoes a severe loss of neurites so that by $3 \mathrm{~d}$ after pupal ecdysis its secondary branches are reduced to short, thickened stumps covered with numerous fine processes (Fig. $1 G$ ). By the time of adult emergence, neurites have grown out to branch extensively over both the contralateral and ipsilateral neuropils. Unlike $\mathrm{MN}-1$, most of the ipsilateral neurites in $\mathrm{MN}-3$ come from contralateral branches that extend across the midline. Approximately half of the adult cells that we examined also have a small ipsilateral branch arising near the cell body and covering the lateral margin of the ipsilateral neuropil (not seen in the example in Fig. $1 H$ ).

MN-1 was selected for a quantitative study of the changes in its neuritic arbor during larval growth and metamorphosis (Figs. $2,3)$. Although both the ipsilateral and contralateral halves of MN-1 undergo marked changes during metamorphosis, our analysis of these changes deals only with the ipsilateral half of the cell. We confined ourselves to this region because parts of the contralateral arbor were obscured by the massive sensory filling usually seen in our backfills (Fig. 4). The youngest celis we filled were from day 2 fourth-stage larvae. During the next $5 \mathrm{~d}$, larvae increase in size from $1 \mathrm{gm}$ to $9-11 \mathrm{gm}$, and the neuropil area within an abdominal ganglion increases by about $50 \%$ (from 13,000 to $20,500 \mu \mathrm{m}^{2}$ ). The sparse ipsilateral neurites grow proportionately, as is shown by the dendritic extent's remaining constant through this period. By the time of pupal ecdysis, the ipsilateral neurites had undergone a slight regression (Figs. 3, 4A). The arbor then remained stable through the next $2 \mathrm{~d}$, followed by the start of neurite outgrowth on day 3 (Fig. $4 B$ ). During the early part of this growth period, the neurites closest to the cell body are advanced in their growth relative to the more medial neurites (Fig. 3, P6, P9; Fig. 4C). In some cells this difference persisted into the adult, whereas in others the medial and lateral sections of the ipsilateral arbor eventually attained equivalent extension. The ipsilateral neurites reached their adult extent by about $12 \mathrm{~d}$ after pupal ecdysis. The emergence of the adult occurred $8 \mathrm{~d}$ later. 


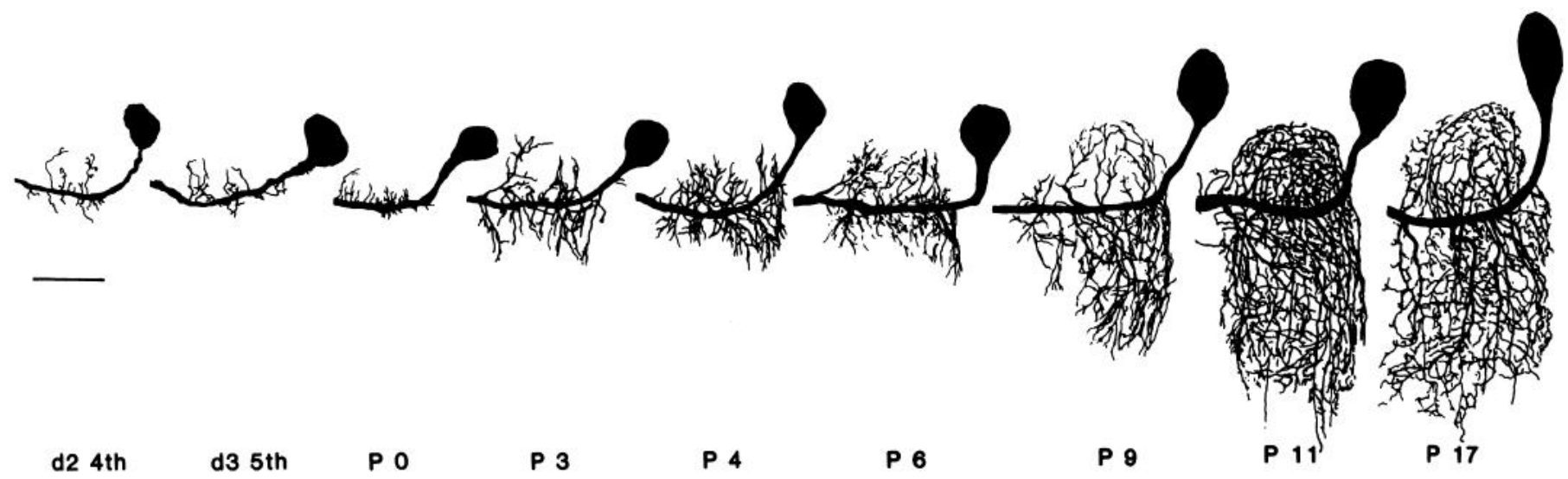

Figure 3. Examples of the ipsilateral arbor of MN-1 as seen from the late fourth instar through adult development. The dendritic extent for the various examples are d2 4th, 0.11 ; 33 th, $0.09 ; \mathrm{P} 0,0.08 ; \mathrm{P} 3,0.23 ; \mathrm{P} 4,0.29 ; \mathrm{P} 6,0.33 ; \mathrm{P} 9,0.50 ; \mathrm{P} 11,0.71 ; \mathrm{P} 17,0.76 . d 2$ 4th. Day 2 of fourth larval stage; $d 35 t h$, day 3 of fifth stage; $P+n o$., the indicated number of days after pupal ecdysis. Scale bar, $50 \mu \mathrm{m}$.

\section{Alternative morphologies for $M N-1$}

In over $90 \%$ of the cells that we examined ( 52 of 57 ), the adult morphology of $\mathrm{MN}-1$ conformed to that depicted in Figure $1 D$. The remaining 5 cells showed an altered morphology such as is seen in Figure $5 \mathrm{~A}$. Its peripheral axon path, cell body position, and pattern of secondary branches in its contralateral arbor clearly identified this neuron as $\mathrm{MN}-1$, but the cell had no caudally directed, ipsilateral branches. Rather, branches extended across the midline from the contralateral arbor into the ipsilateral hemineuropil. A less extreme manifestation of this growth pattern was seen in cells that had some lateral ipsilateral branches but lacked the medial ones. These cells also showed growth from the contralateral arbor into the medial region of the ipsilateral hemineuropil.

None of the larval or early pupal fills of $\mathrm{MN}-1$ that we examined $(n=33)$ showed any branches that extended across the midline from the contralateral arbor. Thus, the altered morphology of the contralateral neurites most likely occurs during the metamorphic growth of the cell rather than during its initial embryonic growth.

Although the altered growth occurs only during adult differentiation, the factors that bias a cell toward such a growth pattern may occur much earlier. For example, Figure $5 B$ shows a cell from a diapausing pupa that had well-resolved fine branches throughout its contralateral arbor but lacked almost all of the ipsilateral branches normally seen at this stage (compare with Fig. 6, $A, B$ ). Since these processes extend to become the major ipsilateral neurites in the adult, their absence may indicate that this cell is incapable of showing ipsilateral neurite outgrowth. We speculate that a deficit in the cell's ability to show such growth results in excess growth from the contralateral side and, hence, in the altered morphology.

The cell in Figure $5 C$ was filled on day 9 after pupal ecdysis,
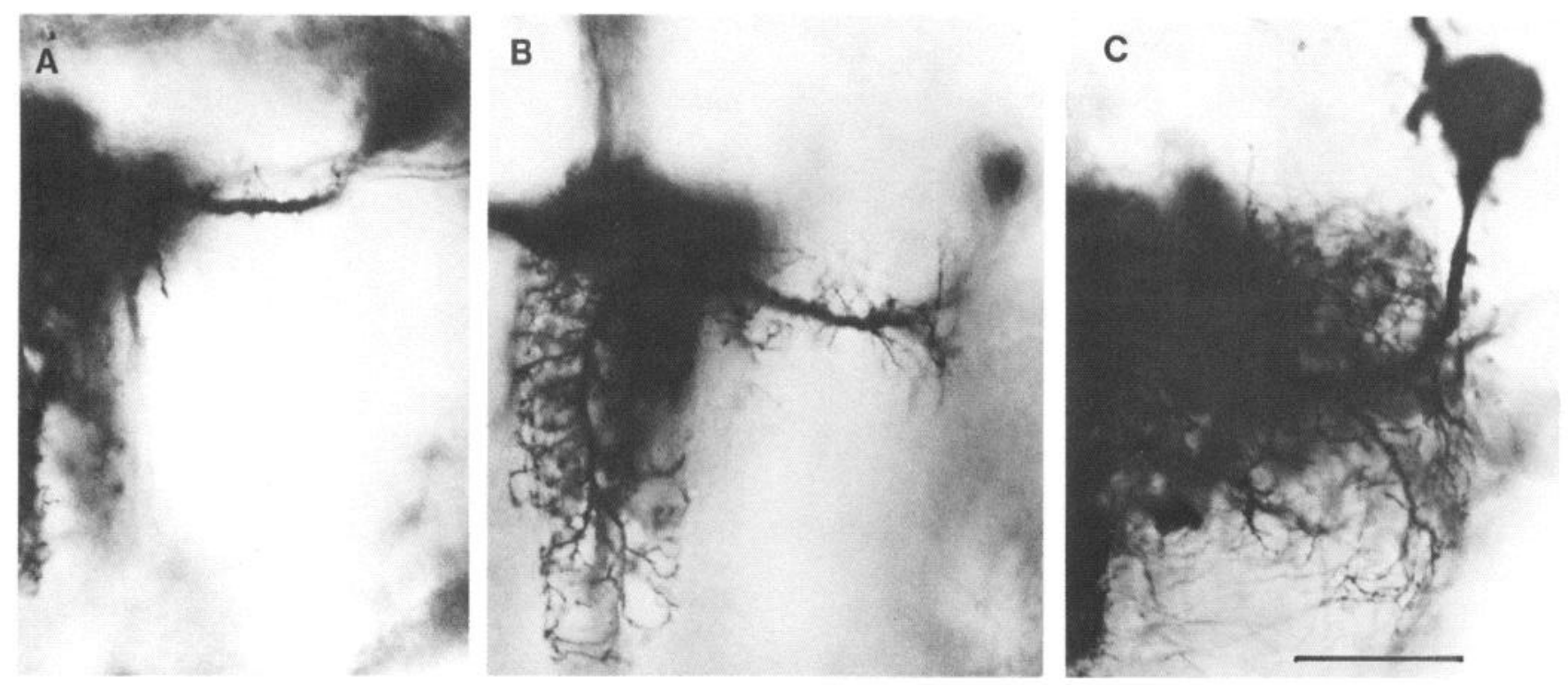

Figure 4. Photomicrographs of whole-mounts of cobalt backfills of MN-1 showing the growth of the ipsilateral arbor from $(A)$ the day of pupal ecdysis through $(B) 3 \mathrm{~d}$ after ecdysis to $(C) 9 \mathrm{~d}$ after pupal ecdysis. Heavy filling of the sensory neuropil ventral to MN-1 obscures the anterior region of the contralateral arbor. Scale, $50 \mu \mathrm{m}$. 


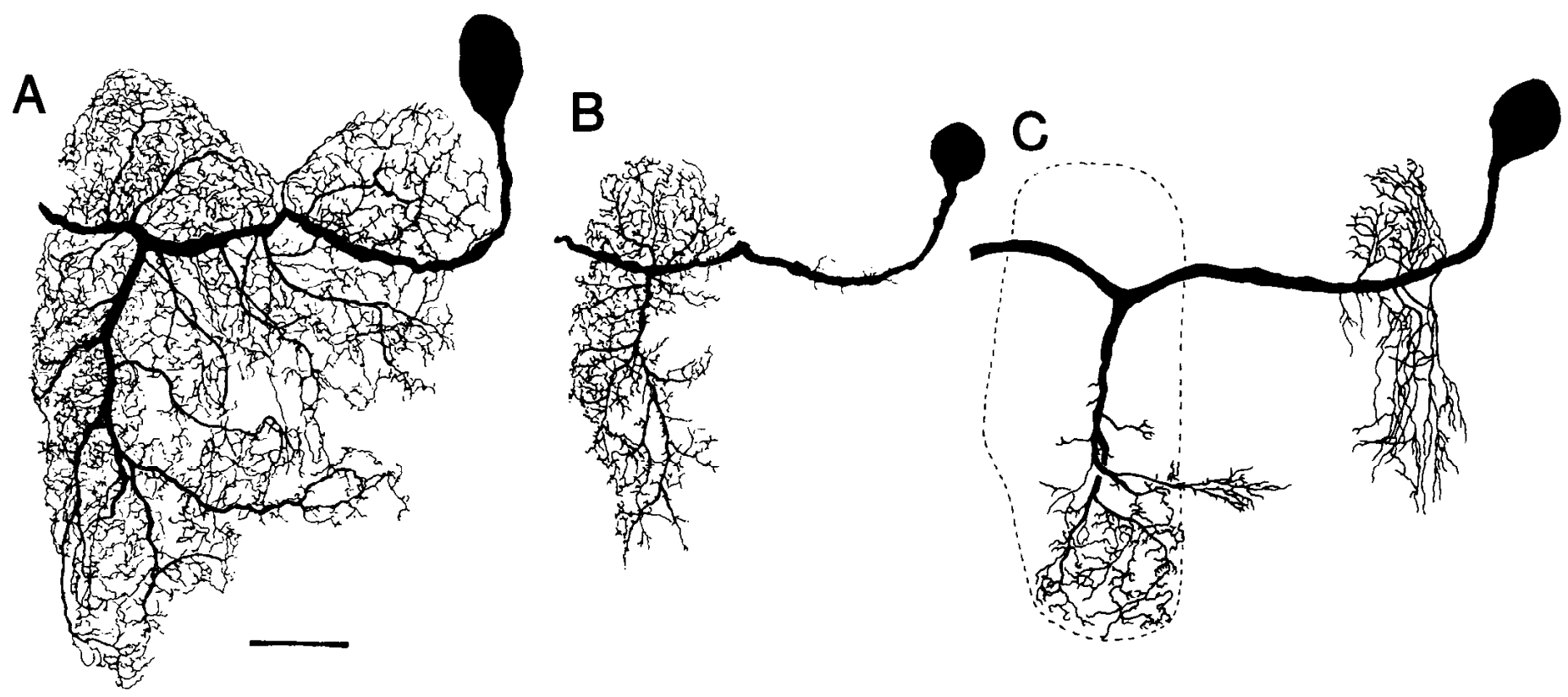

Figure 5. Examples of MN-1 neurons that show atypical patterns of neurite branching. $A$, An adult cell lacking caudally directed branches ipsilateral to the cell body. Note the branches growing across the midline from the contralateral arbor. $B$. A cell from a dispausing pupa that has a normal contralateral arbor but lacks most of the fine branches on the ipsilateral neurite. $C$, A cell from an animal $9 \mathrm{~d}$ after pupal ecdysis. The cell lacks the medial ipsilateral neurites and shows growth across the midline from the contralateral arbor. The rostral portion of the contralateral arbor (dashed outline) was obscured by processes from other cells and could not be drawn. Scale, $50 \mu \mathrm{m}$.

a time when ipsilateral growth is still under way (compare with Fig. 3, P9). Its lateral neurites were past midextension but its medial neurites were absent. But even at this relatively carly stage, the contralateral arbor had a branch that extended across the midline into the posterior region of the ipsilateral neuropil. Hence, the altered growth of the contralateral arbor begins early in the metamorphosis of the cell, well before the ipsilateral arbor is completed. Around this time (days 6-11 after pupal ecdysis) we examined 12 other cells that had normally developing ipsilateral arbors. In all cases, their contralateral arbors were confined to their half of the neuropil. Thus, growth across the midline is not a normal feature of early growth that is later trimmed away as metamorphosis is completed. It appears to be confined only to neurons that lack the normal ipsilateral outgrowth.

Cells that sent major branches across the midline always lacked some or all of their ipsilateral neurites. However, as shown in Figure $1 D$, even examples of $\mathrm{MN}-1$ that have the "classic" morphology show a few twigs that cross the midline in the caudal region of the ganglion. These minor incursions were seen in $60 \%$ of normal cells $(n=52)$. Small processes were seen crossing both from the contralateral to the ipsilateral and vice versa. Thus, growing twigs from $\mathrm{MN}-1$ appear to be able to recognize and follow cues in this pathway, but make little, if any, use of it under normal conditions.

\section{Relationship of process outgrowth to ecdysteroid titers}

Adult differentiation in Manduca is caused by the steroid hormone 20-HE. The ecdysteroid titer rises markedly on the third day after pupal ecdysis, increases until days 9-10, and then declines throughout the remainder of adult development (Bollenbacher et al., 1981; Fig. 2A). As shown in Figure 2B, neurite outgrowth in $\mathrm{MN}-1$ also starts on day 3, coincident with this ecdysteroid rise.

Evidence that ecdysteroids stimulate neurite growth comes from an examination of $\mathrm{MN}-1$ in diapausing pupae. These animals do not secrete the major surge of ecdysteroids after pupal ecdysis (Bowen et al., 1984) and remain in a state of arrested development for months, until ecdysteroids are finally released. In a 3-week-old diapausing pupa, the ipsilateral neuritic field of MN-1 has a dendritic extent of $0.20 \pm 0.04(n=4$; Fig. $6 A)$. This value is greater than that seen at pupal ecdysis $(0.10$; Fig. $2 B$ ) and suggests that neurite growth might occur during diapause in the absence of ecdysteroids. However, MN-1 neurons in pupae that have been in diapause for 19 weeks (Fig. $6 B$ ) have a dendritic extent of $0.22 \pm 0.07(n=5)$, the same as is seen in the younger diapausing pupae. Consequently, the form of $\mathrm{MN}-1$ is stable once the pupa has achieved diapause. The small amount of outgrowth seen in the cell between pupal ecdysis and the diapause condition is presumably due to the low levels of steroid present during the first few days after pupal ecdysis.

Results of preliminary studies of the adult-specific growth of $\mathrm{MN}-1$ confirm that it is indeed caused by ecdysteroids, and are shown in Figure $6 C$. Pupae that had been in diapause for 4 weeks were injected with $10 \mu \mathrm{g} 20$-HE, followed by a second injection $2 \mathrm{~d}$ later. The treatment initiated adult development and, 3 weeks later, when development was csscntially complete, the morphology of MN-1 was examined. Successful fills were achieved in only 2 cases, but in both the ipsilateral arbor of $\mathrm{MN}-1$ showed a dendritic extent in the range found for adults ( 0.76 for the cell in Fig. $6 C$ and 0.83 for the other).

Continuous infusion of ecdysteroid more closely mimics the normal pattern of ecdysteroid secretion. Consequently, we infused diapausing pupae with $2.5 \mu \mathrm{g} 20-\mathrm{HE} / \mathrm{hr}$ over a $12 \mathrm{hr}$ period and then assessed the state of $\mathrm{MN}-1$ at various times thereafter (Table 1). During the first $24 \mathrm{hr}$ there was no change in the state of the ipsilateral neurites. But by $36 \mathrm{hr}$, outgrowth of the neurites had begun; at this time the animal had also initiated adult development. Therefore, ecdysteroids are able to stimulate neurite 

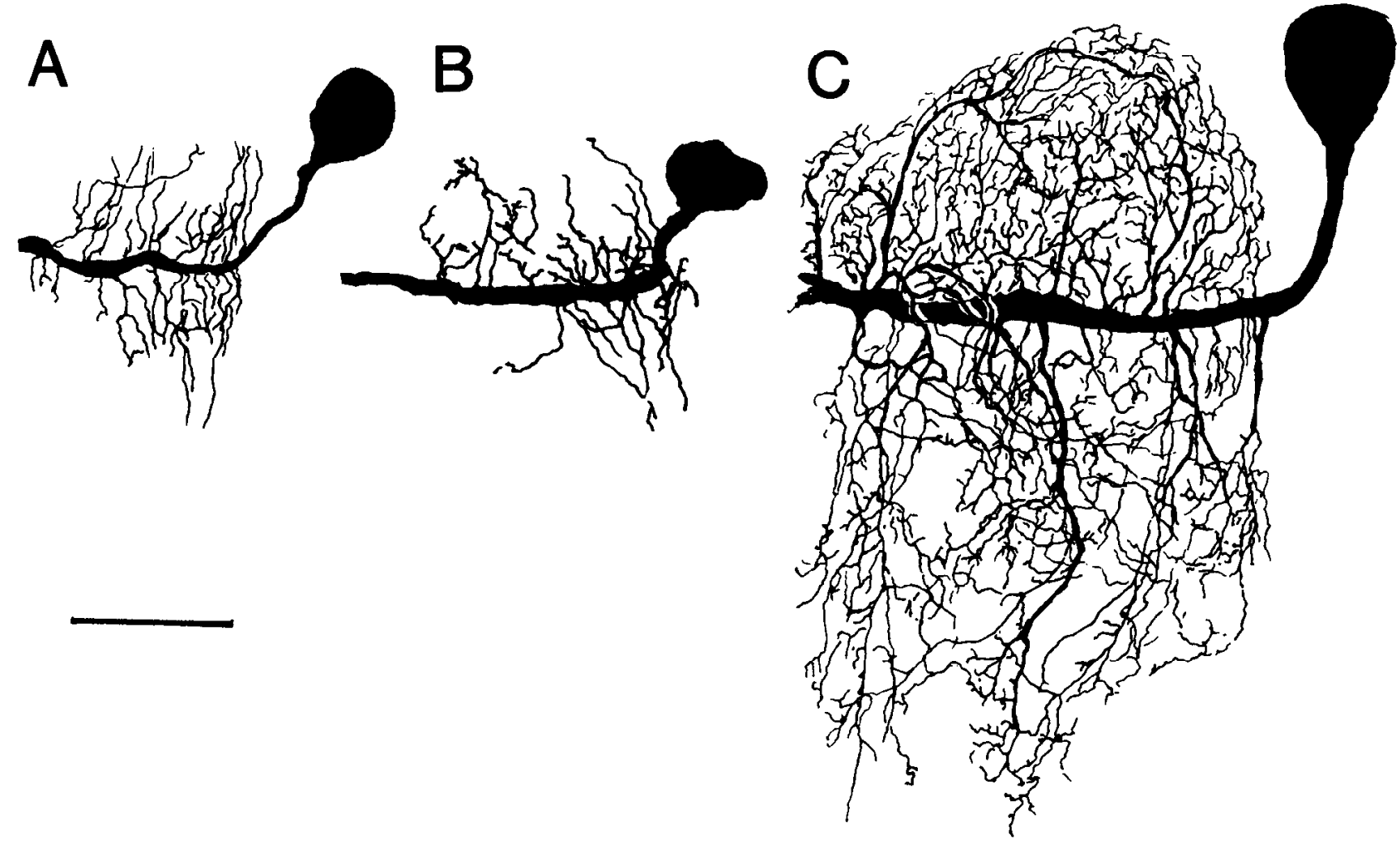

Figure 6. Examples of the ipsilateral dendritic arbor of $\mathrm{MN}-1$ from diapausing pupae. $A$, Cell from an animal that had been in diapause for 3 weeks (dendritic extent, 0.23 ). $B$, Cell from a 19 week diapausing pupa (0.18). $C$, Cell from a diapausing pupa that had been induced to undergo adult development by injection of 20-HE 3 weeks earlier (0.76). Scale, $50 \mu \mathrm{m}$.

outgrowth in a diapausing pupa, but whether this effect is directly on $\mathrm{MN}-1$ or works indirectly through the initiation of adult development is not known.

\section{Effect of juvenile hormone mimics on neurite growth}

Adult differentiation requires the presence of ecdysteroids and the absence of juvenile hormone. Consequently, the application

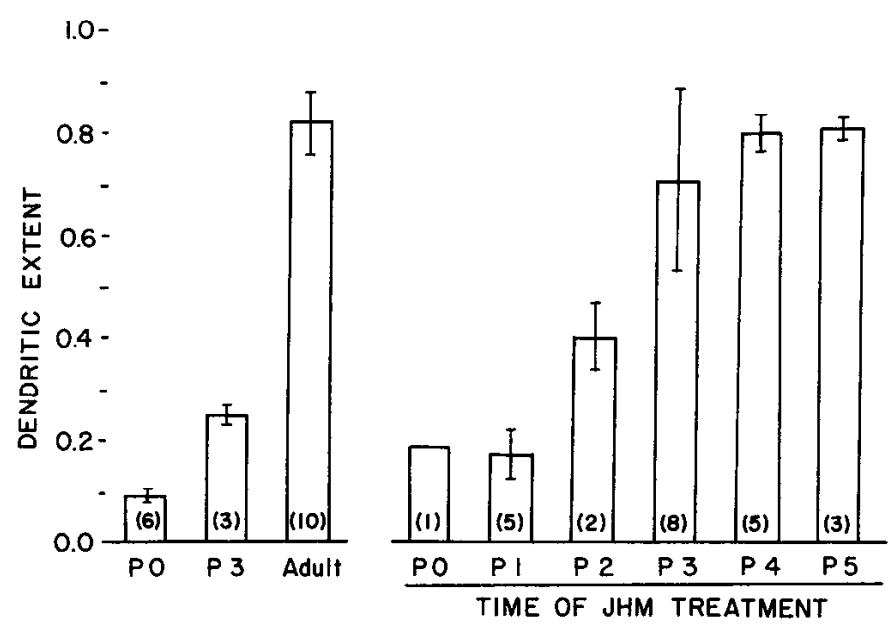

Figure 7. Average dendritic extent of the ipsilateral arbor of MN-1. Left, Values for control animals at the stages indicated. Right, Values from cells taken from adults or pupal-adult intermediates produced by trcatment with JHM at the times indicated after pupal ecdysis $(P O$, etc.). The neurons were filled approximately $2-3$ weeks after the JHM application. The numbers in parentheses are the number of cells examined; the bars give the SD. of $\mathrm{JH}$ or its mimics early in adult development results in the formation of a second pupal stage, rather than in an adult (Riddiford and Ajami, 1973). We challenged Manduca with a standard dosage of JHM (10 $\mu$ g methoprene) at various times after pupal ecdysis. After the completion of the next molt, we then assessed the effect of the treatment on the insect's external morphology and on the morphology of MN-1. The external effects of JHM treatment at various times after pupal ecdysis were in accord with those rcported by Riddiford and Ajami (1973). Treatment within the first $48 \mathrm{hr}$ resulted in pupal-adult intermediates in which most of the head, thorax, and abdomen was covered by pupal cuticle. By $3 \mathrm{~d}$ after pupal ecdysis, JHM treatment produced adults that were normal externally except for pupal cuticle at the injection site and an occasional juvenilization of the genitalia. One day later, the same treatment no longer had any external effects.

The effects of JHM on the morphology of MN-1 paralleled

\begin{tabular}{|c|c|c|}
\hline Treatment & $n$ & $\begin{array}{l}\text { Dendritic extent } \\
( \pm \text { SD) }\end{array}$ \\
\hline Diapausing pupa & 9 & $0.21 \pm 0.05$ \\
\hline $12 \mathrm{hr}$ infusion & 4 & $0.22 \pm 0.06$ \\
\hline $12 \mathrm{hr}$ infusion $+12 \mathrm{hr}$ & 3 & $0.21 \pm 0.05$ \\
\hline $12 \mathrm{hr}$ infusion $+24 \mathrm{hr}$ & 6 & $0.20 \pm 0.06$ \\
\hline $12 \mathrm{hr}$ infusion $+36 \mathrm{hr}$ & 5 & $0.33 \pm 0.05$ \\
\hline
\end{tabular}
at various times after infusion of diapausing pupae with $30 \mu \mathrm{g}$ of 20 - 


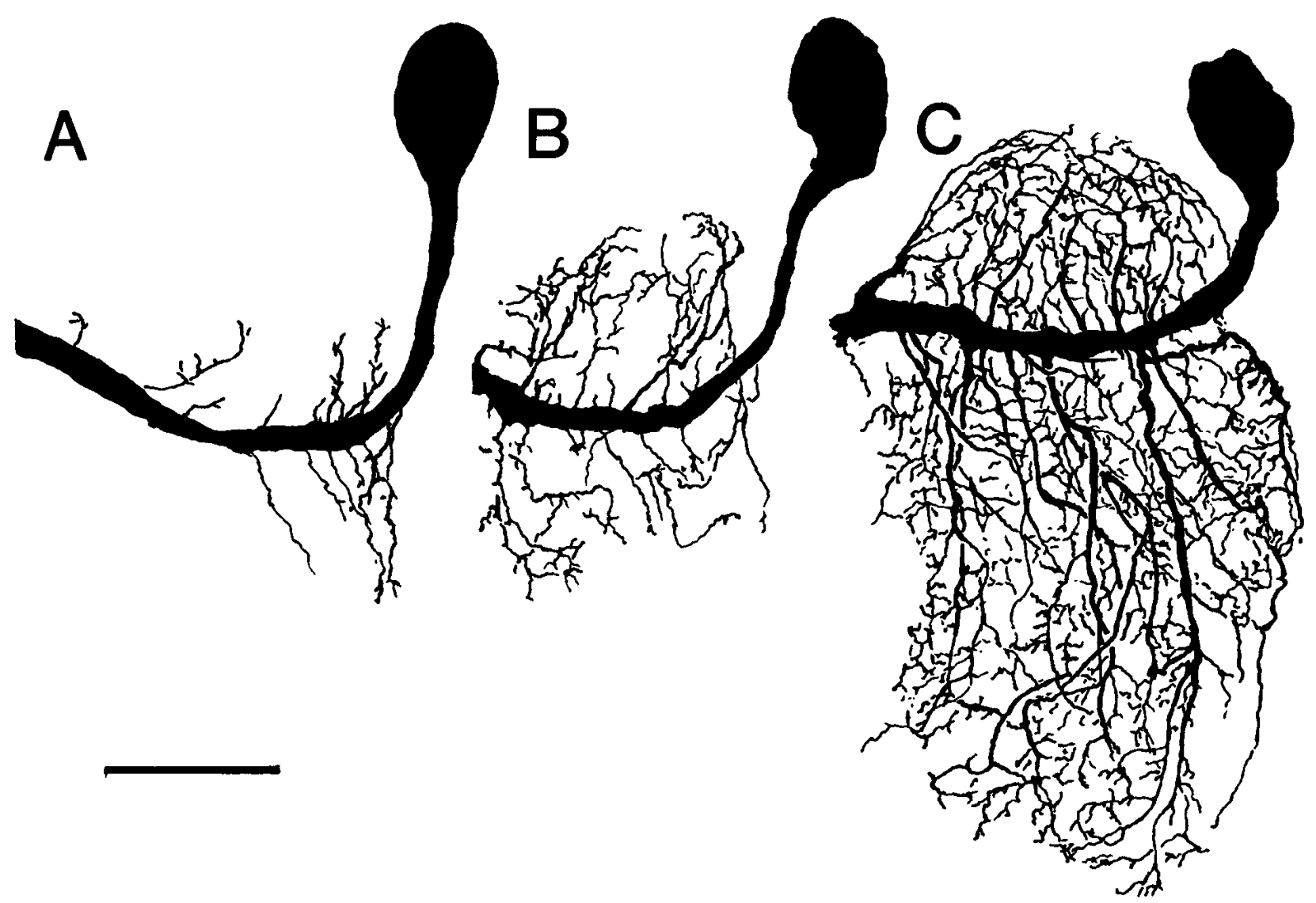

Figure 8. Examples of the ipsilateral arbors of MN-1 from adults or pupal-adult intermediates produced by JIIM treatment. $A$, From a pupaladult intermediate produced by treatment on day P1 (dendritic extent, 0.13 ). B, From an adult with patches of pupal cuticle after treatment on P2 (0.37). $C$, From an essentially normal adult, resulting from treatment on P3 (0.83). Scale, $50 \mu \mathrm{m}$.

its effects on the external morphology. As shown in Figures 7 and 8 , treatment with JHM during the first day after pupal ecdysis resulted in MN-1 neurons that had a dendritic extent only slightly greater than that seen in the new pupa. Nervous systems from animals treated on day 2 were extremely hard to fill and only 2 successful fills were obtained. Both had ipsilateral arbors larger than that seen in the pupa, yet considerably smaller than the full adult arbor. With insects treated on day 3 , most subsequently showed a normal adult shape, although a few were still somewhat retarded in their ipsilateral growth. Insects treated with JHM on subsequent days invariably showed an adult extent of growth after metamorphosis.

As with $\mathrm{MN}-1$, the transformation of $\mathrm{MN}-3$ to its adult form was also affected by JHM treatment. Interestingly, MN-3 differed from MN-1 in the timing of loss of its sensitivity to JHM treatment. As seen in Figures 9 and 10, application of JHM through the fourth day after pupal ecdysis severely retarded the adult-specific outgrowth of this cell. Even on day P5, treatment resulted in adult cells with stunted arbors. MN-3 only became aloof to JHM 6-7 d after pupal ecdysis.

The above data indicate that MN-1 and MN-3 differ in the timing of their responses to JHM. In a few instances, for animals treated on day 4 we filled the entire dorsal nerve rather than the respective branches, so that both neurons were filled. The large number of neurites that filled in these cases made it difficult to unravel where some of the finer twigs belonged, but the main ipsilateral processes of the 2 cells were easily distinguished. In these cases, even though they resided in the same ganglion, MN-1 typically showed an adult morphology, whereas MN-3 was pupal in its appearance. This difference is illustrated by the example in Figure 11, in which MN-1 and MN-3 are filled in successive ganglia from an animal that had been treated with JHM on day 4 and allowed to finish adult development. MN-1

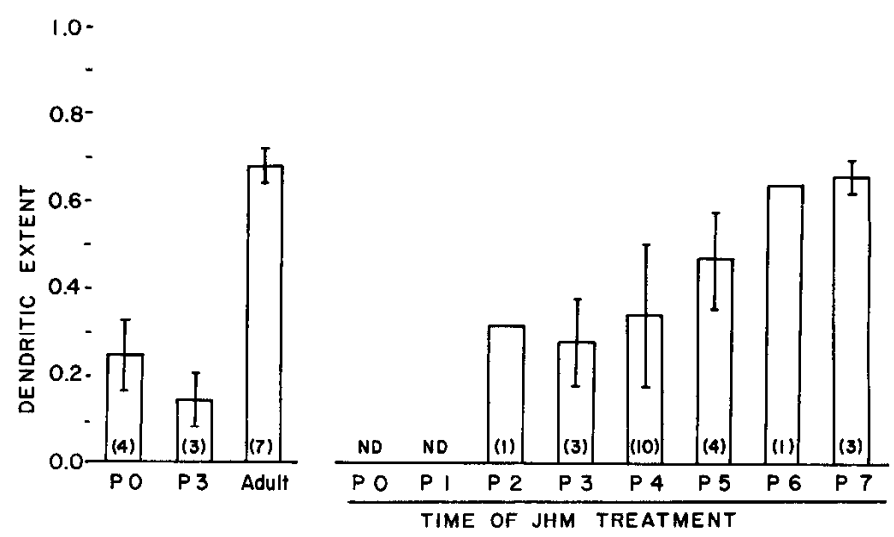

Figure 9. Average dendritic extent of the ipsilateral portion of $\mathrm{MN}$ 3. Left, Values for cclls from control animals at the stages indicated. Right, Values from cells taken from adults after treatment with JHM at the times indicated after pupal ecdysis $(P O$, etc.). $N D$. Not determined; remainder as in Figure 7. 

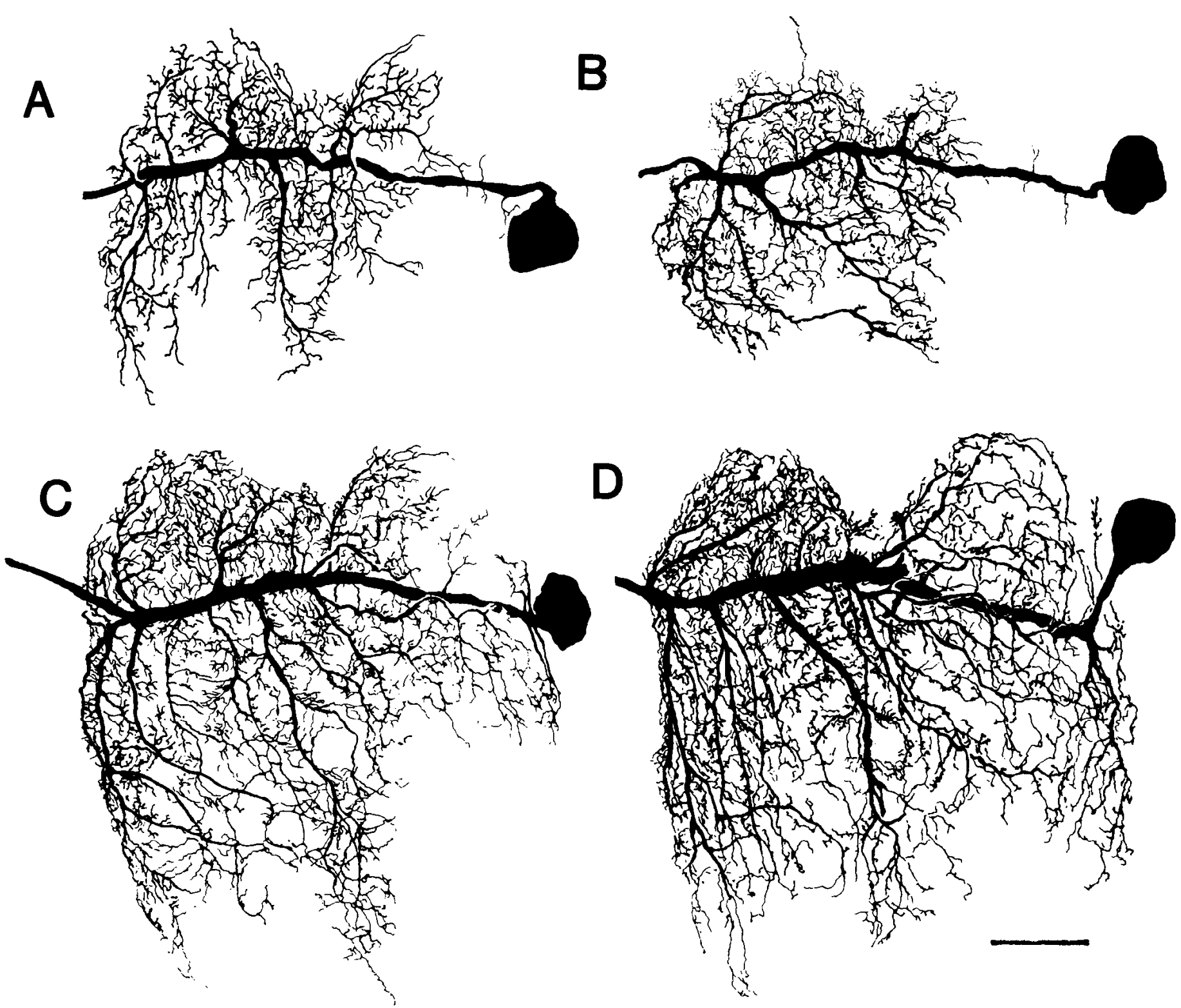

Figure 10. Examples of the morphology of MN-3 from adults that had received JHM at various times after pupal ecdysis. $A, B$, Treatment on day 4 after pupal ecdysis. $C$, On day 5. $D$, On day 6 . In all cases the adults had normal external morphology. Scale, $50 \mu \mathrm{m}$.

continued on its pattern of adult-specific growth, whereas growth of $\mathrm{MN}-3$ was inhibited.

\section{Discussion}

Metamorphosis of the CNS of holometabolous insects is achieved by the addition of new neurons (Booker and Truman, 1987) and by extensive remodeling of pre-existing cells (Casaday and Camhi, 1976; Truman and Reiss, 1976; Levine and Truman, 1985). In the latter case, the postembryonic life of neurons such as $\mathrm{MN}-1$ and $\mathrm{MN}-3$ is divided into 3 phases. In the larva, the neuron grows allometrically, in concert with the growth of the insect. In this phase, the neurons are similar to central neurons of hemimetabolous insects, such as grasshoppers, in which the dendritic arbor of a neuron in the adult is an enlarged version of that seen at the time of hatching (e.g., Shankland and Goodman, 1982). At metamorphosis, however, neurons of holometabolous insects divert from the hemimetabolous pattern and enter a second phase in which a greater or lesser amount of the larval neuritic tree is lost (Fig. 1; Weeks and Truman, 1985). The third phase then follows, during adult development, with the outgrowth of new, adult-specific arbors.

The motoneurons studied by Weeks and Truman (1985) and those in the present report differ in the extent of neurite loss during the larval-pupal transition. The losses of larval neurites were relatively minor in $\mathrm{MN}-1$, moderate to extreme in APR and PPR (Weeks and Truman, 1985), and severe in MN-3. The cause of this variability is not clear. It may reflect the number of larval connections still in use in the pupal stage, or, alternately, the number that are fated to persist into the adult stage. If the latter were the case, one would expect the larval and adult forms of MN-1 to share many common inputs, whereas the respective forms of MN-3 share relatively few. Such comparative data are not yet available. Irrespective of the basis for the variation in the extent of loss, the fact that larval branches are lost argues that the larval form of the cell is not achieved simply by arresting the growth of the cell at an intermediate point in 


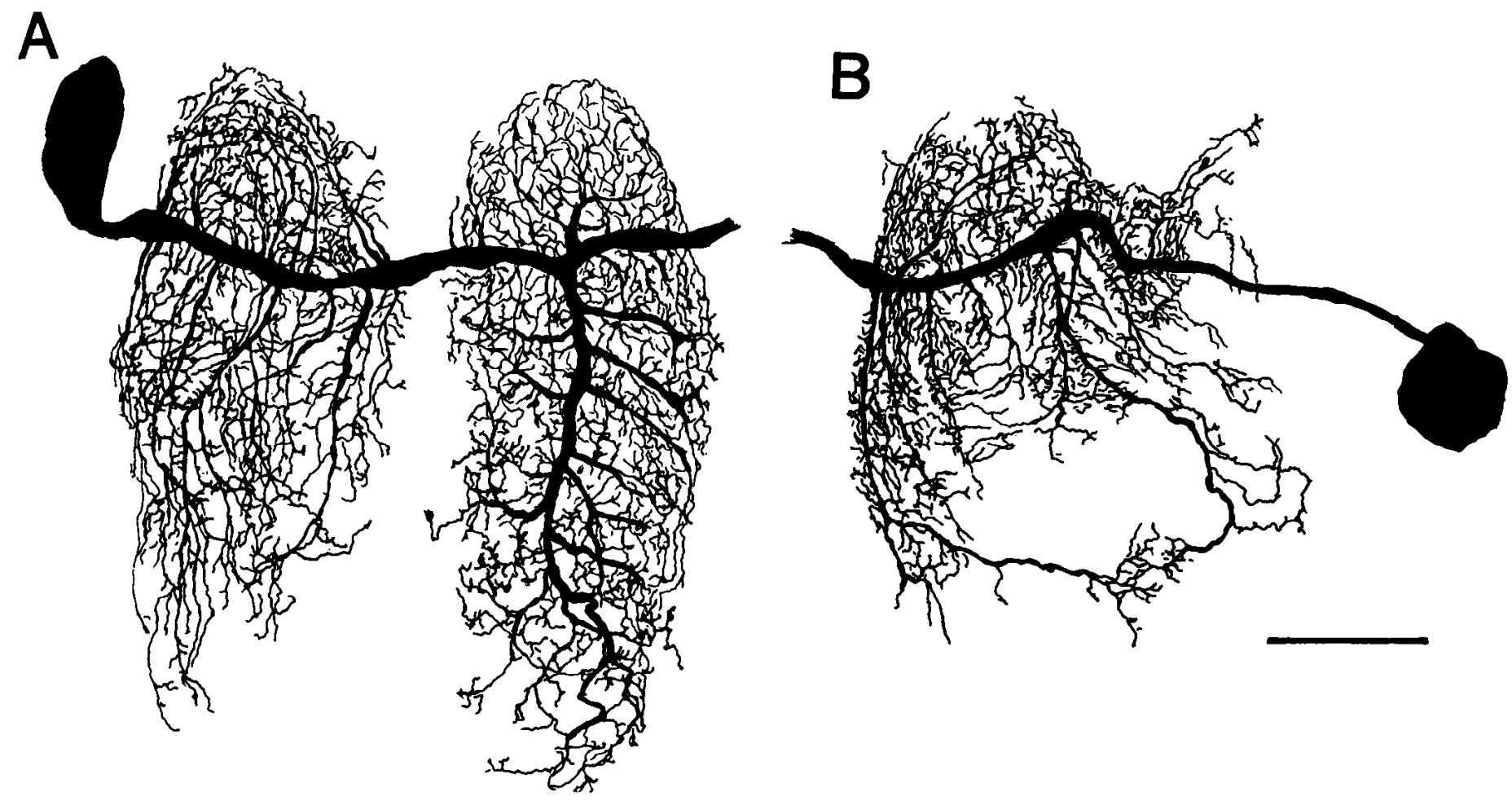

Figure 11. An example of $(A) \mathrm{MN}-1$ and $(B) \mathrm{MN}-3$ from a moth that had developed from a pupa treated with JHM on day 4 after pupal ecdysis. MN-1 underwent normal adult outgrowth, whereas MN-3 was severely inhibited. The neurons were from ganglia A4 and A5, respectively. Scale, $50 \mu \mathrm{m}$.

the development of the adult form. Rather, the larval cell has its own specializations that adapt it to larval behavior and that are lost before the adult form is produced.

Neurite extension in $\mathrm{MN}-1$ begins on the third day after pupal ecdysis, a time corresponding to the initiation of adult development of the insect as a whole, and proceeds until about day 11 or 12. This timing of neurite extension is similar to that seen for the ingrowth of antennal afferents during the metamorphosis of the brain (Hildebrand, 1980). In the latter system, fiber ingrowth is then followed by synaptogenesis up through day 13 . Presumably the establishment of new synaptic contacts onto motoneurons also occurs during this same period. Indeed, in the thoracic ganglia, the remodeled flight motoneurons (Casaday and Camhi, 1976; J. W. Truman, unpublished observations) can be synaptically driven midway through adult development and begin patterned activity a few days later (Kammer and Kinnamon, 1979).

The contralateral and ipsilateral arbors of the adult $\mathrm{MN}-1$ cover similar extents of neuropil and are thought to receive similar synaptic inputs (Levine and Truman, 1982). However, the manner by which the 2 arbors cover their respective hemineuropils is quite different. The contralateral arbor, which was formed during embryogenesis, shows little variation in its main branches, which consist of a single primary neurite that gives rise to a stereotyped array of secondary branches (Truman and Reiss, 1976). By contrast, the adult-specific field consists of numerous parallel branches, none of which assumes a dominant status. The latter pattern of growth through the extension of parallel branches is also seen in the Cardioacceleratory Peptide (CAP) neurons (Tublitz and Truman, 1985), which are born during larval life and also undergo neurite growth during metamorphosis. These cells are extremely variable, even as to which neurites eventually become the pcripheral axons (Taghert, 1981). The reason for this difference in embryonic and postembryonic neurite growth is unclear. The embryonic motoneurons are among the first neurons to differentiate and their neurites grow through a landscape that is relatively open and simple (Bastiana et al., 1984). By contrast, metamorphic growth occurs within a compact, functioning $\mathrm{CNS}$, and the reduction in morphological stereotypy may indicate that neurite pathfinding is more difficult in the latter environment.

The alternative forms of $\mathrm{MN}-1$ pose questions as to the factors that regulate the growth of neuritic arbors. A number of studies in arthropods have focused on the role of afferent inputs in determining the form of dendritic trees. For example, by cercal removal in embryonic grasshoppers, Shankland et al. (1982) showed that the final pattern of dendritic branching of the medial giant interneuron (MGI) is shaped by the balance of afferent innervation. They suggested that the apparent antagonistic growth of the various branches might occur if each competed for limited resources (e.g., intracellular signals or construction materials) and innervation of a particular branch somehow diverted to it a greater amount of these resources. These deafferentations, however, altered only the final form of the cell, not its initial pattern of neurite outgrowth. Thus, there are earlier events in the development of a neuron before the arrival of afferents that determine from where its major branches will grow.

Although it is most likely that presynaptic inputs also influence the shape of the neuritic arbors of $\mathrm{MN}-1$, we have no reason to suspect that the altered forms shown in Figure $5 \mathrm{~A}$ result from abnormal presynaptic inputs. Cells like those in Figure $5, B, C$ suggest that the adult growth of the altered MN-1 neurons is abnormal from its inception. Consequently, we favor the interpretation that the primary deficit is in an early process that 
establishes where the major neurites will arise. With the start of neurite extension at the beginning of adult development, the lack of ipsilateral neurites would then cause additional material to be shunted to the contralateral arbor, resulting in its abnormal extension. The excessive growth of major contralateral branches allows them to extend along pathways (e.g., the posterior commissures) that are normally used only by the small twigs. Once in the other hemineuropil, these branches are presumably stabilized by receiving inputs originally destined for the ipsilateral neurites.

\section{Role of hormones in regulating neuronal growth}

Gonadal steroids promote the growth of neuronal cell bodies and dendritic arbors in a number of vertebrates (Gurney, 1981; Arnold and Gorski, 1984; Breedlove, 1986). In insects another class of steroids, the ecdysteroids, also have profound effects on neuronal size and shape, but their actions are complex and are modulated by the presence of a second hormone, JH. Ecdysteroids are released periodically during larval life to cause larval molting. We have no evidence that these ecdysteroid releases affect the first phase of neuronal growth, when MN-1 is increasing in size in concert with the growing larva. Indeed, growth within the larval CNS occurs primarily during the intermolt (Edwards, 1969), when the larva is feeding and ecdysteroids are absent. JH is present throughout larval life and its presence presumably prevents the ecdysteroids from causing the morphological changes characteristic of metamorphosis. Accordingly, application of JHM to fifth-stage larvae results in a supernumerary molt to giant sixth-stage larvae that have giant, albeit larval, forms of MN-1 (J. W. Truman, unpublished obscrvations).

After the disappearance of $\mathrm{JH}$ permits the onset of metamorphosis, the ecdysteroids exert a profound effect on neuronal morphology. Neurons such as MN-1, MN-3, and PPR (Weeks and Truman, 1985) undergo losses of neurites during the larvalpupal transition. Studies on PPR showed that the prepupal ecdysteroid peak, which causes pupal differentiation, also causes the neurite loss in this cell. This loss can be prevented by application of exogenous $\mathrm{JH}$, but it must be given prior to the small peak of ecdysteroids that occurs just prior to wandering (Fig. 2A; Weeks and Truman, 1986).

This paper has focused primarily on the role of hormones in the third phase, the time of extension of the adult neurites. MN-1 begins neurite outgrowth $3 \mathrm{~d}$ after pupal ecdysis, at the same time that the ecdysteroid titer starts to rise (Bollenbacher et al., 1981). It fails to grow during diapause, which is maintained by the absence of ecdysteroids, but infusion of $20-\mathrm{HE}$ promotes neurite outgrowth. It is interesting that the same hormone causes opposite responses (regression versus outgrowth) in the same cell depending on when it is given. We have not yet determined whether it is possible to make a larval cell skip the regression phase by exposing it to the endocrine environment characteristic of adult development. We suspect that the developmental history of the cell will also prove to be important in determining the nature of its response to the ecdysteroid cue.

Application of JHM early in adult development prevented the outgrowth of the adult neurites. It should be noted in the examples in Figures 8 and 10 that the severely affected cells showed an increase in cell body size to adult dimensions even though they showed little neurite growth. Thus, JHM does not interfere with cell growth in general, but only with the metamorphic aspects of this growth.
MN-1 and MN-3 differ markedly in the time at which they lose sensitivity to JHM application. The end of MN-1's sensitive period coincides with the start of neurite extension on day 3 . MN-3 is sensitive until a few days later, and preliminary evidence suggests that the onset of adult outgrowth in MN-3 is similarly delayed (S. E. Reiss and J. W. Truman, unpublished observations). These correlations suggest that the sensitivity of a neuron to $\mathrm{JH}$ ends once the cell initiates its adult program of growth.

The results of a number of studies on Manduca suggest that the ecdysteroids and JH may be acting directly on central neurons. Experiments with cultured ganglia showed that ecdysteroids added to the medium prevented the neuronal death that normally occurs after adult emergence (Bennett and Truman, 1985). Ecdysteroid infusion induces neurite regression in PPR even in the absence of the neuron's target muscle, which normally also dies at this time (Weeks and Iruman, 1985). Direct evidence that motoneurons are ecdysteroid targets comes from autoradiographic studies showing that a subset of these cells concentrate radiolabeled ecdysteroids in their nuclei (S. E. Fahrbach and J. W. Truman, unpublished observations). In the case of $\mathbf{J H}$, the best evidence for a direct action comes from the study by Levine et al. (1986) showing that local application of JHM to a small patch of larval integument results in the respective sensory neurons' retaining their larval form in a nervous system that is otherwise completely pupal. At this time we do not know whether the ecdysteroids and JH act directly on $\mathrm{MN}-1$ and $\mathrm{MN}-3$ to regulate neurite outgrowth, or indirectly through actions on presynaptic or postsynaptic targets. Clearly, the responses shown by animals treated with JHM on days 4 and 5 show that the adult outgrowth of the cells is not causally linked to the action of these hormones in the metamorphosis of the integument and the associated ingrowth of adult afferents.

\section{References}

Alley, K. E., and M. D. Barnes (1983) Birth dates of trigeminal motoneurons and metamorphic reorganization of the jaw myoneural system in frogs. J. Comp. Neurol. 218: 395-405.

Arnold, A. P., and R. A. Gorsky (1984) Gonadal steroid induction of structural sex differences in the central nervous system. Annu. Rev. Neurosci. 7: 413-442.

Bacon, J. P., and J. S. Altman (1977) A silver intensitication method for cobalt filled neurons in whole mount preparations. Brain Res. 138: 359-363.

Barnes, M. D., and K. E. Alley (1983) Maturation and recycling of trigeminal motoneurons in anuran larvae. J. Comp. Neurol. 218: $406-414$.

Bastiani, M. J., J. A. Raper, and C. S. Goodman (1984) Pathfinding by neuronal growth cones in grasshopper embryos. III. Selective affinity of the $G$ growth cones for the P cells within the A/P fascicle. J. Neurosci. 4: 2311-2328.

Bell, R. A., and F. A. Joachim (1976) Techniques for rearing laboratory colonies of tobacco hornworms and pink bollworms. Ann. Entomol. Soc. Am. 69: 365-373.

Bennett, K. L., and J. W. Truman (1985) Steroid-dependent survival of identifiable neurons in cultured ganglia of the moth Manduca sexta. Science 229: 58-60.

Bollenbacher, W. E., S. L. Smith, W. Goodman, and L. I. Gilbert (1981) Ecdysteroid titer during larval-pupal-adult development of the tobacco hornworm, Manduca sexta. Gen. Comp. Endocrinol. 44: 302306.

Booker, R., and J. W. Truman (1987) Postembryonic ncurogenesis in the CNS of the tobacco hornworm, Manduca sexta. I. Neuroblast arrays and the fate of their progeny during metamorphosis. J. Comp. Neurol. 255: 548-559.

Bowen, M. F., W. E. Bollenbacher, and L. I. Gilbert (1984) In vitro studies on the role of the brain and prothoracic glands in the pupal diapause of Manduca sexta. J. Exp. Biol. 108: 9-24. 
Breedlove, S. M. (1986) Cellular analysis of hormone influence on motoneuronal development and function. J. Neurobiol. 17: 157-176.

Casaday, G. B., and J. M. Camhi (1976) Metamorphosis of flight motoneurons in the moth Manduca sexta. J. Comp. Physiol. 112: 143-158.

Curtis, A. T., M. Hori, J. M. Green, W. J. Wolfgang, K. Hiruma, and L. M. Riddiford (1984) Ecdysteroid regulation of the onset of cuticular melanization in allatectomized and black mutant Manduca sexta larvae. J. Insect Physiol. 30: 597-606.

DeVoogd, T. J., and F. Nottebohm (1981) Sex differences in dendritic morphology of a song control nucleus in the canary: A quantitative Golgi study. J. Comp. Neurol. 196: 309-316.

Edwards, J. S. (1969) Postembryonic development and regeneration of the insect nervous system. Adv. Insect Physiol. 6: 97-137.

Ephrussi, B., and G. W. Beadle (1936) A technique of transplantation for Drosophila. Am. Nat. 70: 218-225.

Greenough, W. T., C. S. Carter, C. Steerman, and T. J. DeVoogd (1977) Sex differences in dendritic patterns in hamster preoptic area. Brain Res. 126: 63-72.

Gurney, M. E. (1981) Hormonal control of cell form and number in the zebra finch song system. J. Neurosci. 1: 658-673.

Hildebrand, J. G. (1980) Development of putative acetylcholine receptors in normal and deafferented antennal lobes during metamorphosis of Manduca sexta. In Receptors for Neurotransmitters, Hormones and Pheromones in Insects, D. B. Sattelle, L. M. Hall, and J. G. Hildebrand, eds., pp. 209-220, Elsevier/North Holland, Amsterdam.

Hoskins, S. G., and P. Grobstein (1985) Development of the ipsilateral retinothalamic projection in the frog Xenopus laevis. III. The role of thyroxine. J. Neurosci. 5: 930-940.

Kammer, A. E., and S. C. Kinnamon (1979) Maturation of the flight motor pattern without movement in Manduca sexta. J. Comp. Physiol. 130: 29-37.

Kelley, D. B., and S. B. Fenstemaker (1983) Sexually dimorphic neurons of the vocal production nucleus in Xenopus laevis. Soc. Neurosci. Abstr. 9: 1094.

Kollros, J. J. (1981) Transitions in the nervous system during amphibian metamorphosis. In Metamorphosis: A Problem in Developmental Biology, L. I. Gilbert and E. Frieden, eds., pp. 445-459, Plenum, New York.

Kurz, E. M., D. R. Sengelaub, and A. P. Arnold (1985) Androgenic regulation of dendritic arbors in a sexually dimorphic rat spinal nucleus. Soc. Neurosci. Abstr. 11: 529.

Levine, R. B., and J. W. Truman (1982) Metamorphosis of the insect nervous system: Changes in morphology and synaptic interactions of identified neurons. Nature 299: 250-252.
Levine, R. B., and J. W. Truman (1985) Dendritic reorganization of abdominal motoneurons during metamorphosis of the moth Manduca sexta. J. Neurosci. 5: 2424-2431.

Levine, R. B., J. W. Truman, D. Linn, and C. M. Bate (1986) Endocrine regulation of the form and function of axonal arbors during insect metamorphosis. J. Neurosci. 6: 293-299.

McLaughlin, B. J. (1974) Fine-structural changes in a lepidopteran nervous system during metamorphosis. I. Cell Sci. 14: 369-387.

Meltzer, Y. L. (1971) Hormonal and Attractant Pesticide Technology, Noyes Data Corp., Park Ridge, NJ.

Riddiford, L. M., and A. M. Ajami (1973) Juvenile hormone: Its assay and effects on pupae of Manduca sexta. J. Insect Physiol. 19: 749 762.

Schwartz, L. M., and J. W. Truman (1983) Hormonal control of rates of metamorphic development in the tobacco hornworm Manduca sexta. Dev. Biol. 99: 103-114.

Shankland, M., and C. S. Goodman (1982) Development of the dendritic branching pattern of the medial giant interneuron in the grasshopper embryo. Dev. Biol. 92: 489-506.

Shankland, M., D. Bentley, and C. S. Goodman (1982) Afferent innervation shapes the dendritic branching pattern of the medial giant interneuron in grasshopper embryos raised in culture. Dev. Biol. 92: 507-520.

Taghert, P. H. (1981) The Identification and Analysis of Specific Peptide-Containing Neurons in the Moth, Manduca sexta. Ph.D. dissertation, University of Washington, Seattle, p. 134.

Thomas, J. B., M. J. Bastiani, M. Bate, and C. S. Goodman (1984) From grasshopper to Drosophila: A common plan for neuronal development. Nature 310: 203-207.

Truman, J. W., and S. E. Reiss (1976) Dendritic reorganization of an identified motoneuron during metamorphosis of the tobacco hornworm moth. Science 192: 477-479.

Tublitz, N. J., and J. W. Truman (1985) Intracellular stimulation of an identified neuron evokes cardioacceleratory peptide release. Science 228: 1013-1015.

Weeks, J. C., and J. W. Truman (1985) Independent steroid control of the fates of motoneurons and their muscles during insect metamorphosis. J. Neurosci. 5: 2290-2300.

Weeks, J. C., and J. W. Truman (1986) Hormonally mediated reprogramming of muscles and motoneurones during the larval-pupal transition of the tobacco hornworm, Manduca sexta. J. Exp. Biol. 125: $1-13$.

White, J. G., D. G. Albertson, and M. A. R. Anness (1978) Connectivity changes in a class of motoneuron during the development of a nematode. Nature 271: 764-766. 